\title{
DEGRADATION OF METAL OXIDE SURGE ARRESTERS UNDER SIMULATED NATURAL CONDITIONS
}

\author{
P.M. Vipin, N.K. Kishore, G.R. Nagabhushana and B.N. Jayaram, \\ Department of High Voltage Engineering. \\ Indian Institute of Science. \\ Bangalore 560012
}

\begin{abstract}
The degradation of metal oxide surge arresters (MOSA) under continous operating voltage (C.O.V), with time, is a well known fact. But the contribution of transient overvoltages in the form of lightning surges, switching surges etc.,against which the arrester is used as a protection device, to the arrester degradation has not been studied much. The simulation of a situation, wherein the arrester is kept uder c.o.v and different surges are applied on it, is somewhat complex. A method for simulation of field operating conditions of an arrester in the laboratory is presented in this paper. Results of two seperate degradation studies on different samples under A.C and D.C excitations with superimposed transient stresses - are given. A comparison of observed data with calculated ones is al so made.
\end{abstract}

\section{INTRODUCTION}

Developments in material technology have spurred quantum advances in power system equipment protection within the past two decades. Eversince its advent, around $1970^{\prime}$ s, metal oxide based surge arresters have emerged as the most reliable device aqainst power system transient overvoltages. It is being increasingly used in surge protection due to its superior nonlinear characteristics and greater energy handling capabilities. But, due to the absence of any series isolating gaps, the surge arrester elements are continousiy stressed by the system voltage, which causes the flow of a small leakage curent (about $50 \mu \mathrm{A}$ or so). This current as well as the energy absorption at the time of impulse discharges, cause gradual degradation of the elements. In order to predict the period of reliable operation of a metal oxide surge arrester, or its life, the degradation phenomena is studied the worldover. Still, a definite procedure is yet to be postulated to assess degradation under both A.C and D.C excitations. Here we present the results of work done in our laboratory to study the degradation of surge arrester elements under simulated natural conditions.

\section{EXPERIMENT}

\subsection{Scheme of experiment}

The representation of thr sivil., conditions is achieved by estimiting I lu stress cycle per year. This cycla is then applied to the surge arrestri element over one day, to simulato thr electrical stresses coming upon the arrester under field conditions. $\lambda$ typical transient stress cycle over "mr. year has been broadly estimalinl is follows:

(i) Lightning transients

(a) direct stroke, simulated by + surge current of $4 / 10 \mathrm{ks}, 50 \mathrm{kA}$ postulated to occur onco crerl 5 years.

(b) indirect strokes, simulatorl b) surge currents of $\pi / 20 / \mu$ duration and magnitudes 5,10 and 20kA occurilly respectively: at frecurencir:s of roughly 18,5 and 2 tincs an year.

(ii) Switching transients simulatid by rectangular cureent [u] "ir w 1kA magnitude and 2.4m: pulsewidth, occurring once in an year:

While the above transients are applied the arrester is kept undry continous operating voltage $(\mathrm{C} . \mathrm{O} . \mathrm{V})$ at a

temperature of $60 \mathrm{C}$. Experiments were carried out with D.C and A.C cxcitations applied to the arrester elements. The 0

elevated temperature of $60 \mathrm{C}$ simmlatirs the maximum probable element temprcathr. in field service, taking into accomm the influence of ambient temperaturo. solar radiation and influcm." " pollution on the arrester housing 111 . Eurther, one year field lifr wr th. arrester is simulated within onc 1.r following the accelerated aying procedure described in clause 61.2 "if IEC TC 37 WG-4 AUGUST 1988 documnat r.. MOSA. Accordingly, after the ablu iratim of surges the sample was healed 11, 
0

temperature of $115+/-4 \mathrm{C}$ and kept at that temperature with the C.O.V across it, .till the start of the next aging cycle.: A 20 day simulation on the above lines was carried out with, minimum interruption of the A.C operating voltage across the arrester element. Another 10 day experiment with. D.C operating voltage on a different sample was a iso conducted.

\section{2,2 . Instrumentation}

The lightning impulse current's were generated using a capacitor discharge. One generator was capable of giving upto $40 \mathrm{kA}, i .8 / 20 \mu \mathrm{s}$ and another generator of $200 \mathrm{kA},: 4 / 10 \mu \mathrm{s}$. The switching impulse current. was obtained from a 8 stage ladder network transmission line model. It had a surge impedance of $3.6 \mathrm{ohms}$ and the output pulse width was $2.4 \mathrm{~ms}$. The A.C/D.C excitation for the arrester elements was obtained from a $230 \mathrm{~V} / 3.6-0-$ $3.6 \mathrm{kV}, 0.5 \mathrm{kVA}$, oil filled transformer and half-wave rectifier \& filter capacitor arrangement. The arrester element was kept inside a temperature controlled oven to maintain the elevated temperatures. The oven bad a maximum temperature capability of $30.0^{\circ} \mathrm{C}$ with a

$+1-2$ C regulation.

The measuring instrumentation comprised of a $17.5 \mathrm{~m} \Omega$ co-axial current shunt with. Gould 4074 100MHz Digital storage Oscilloscope, for measuring impulse currents and a resistance potential divider to monitor the residual voltage across the arrester as well as the C.o.v. Typical $8 / 20 \mu \mathrm{s}$ lightning impulse current and $2.4 \mathrm{~ms}$ Iswitching impulse current waveforms. obtained using the above arrangement are shown in Fig.1. The leakage current through the arrester element was monitored using a series resistancedigital. multimeter scheme. The capacitance and tan delta variation with aging. was measured using GENRAD RLC Digibridge Type 1657 .

\section{RESULTS}

The variation in the different degradation indices monitored are graphically depicted in Figs. 2 to 10 as a function of the aging cycles. Eventhough the leakage current and barrier height were the main indices monitored, capacitance and tan delta variations are also shown.

\subsection{Lèkage current:}

Inspite of the scatter observed, the leakage current shows significant overall increase after successive aging cycles under both A.C and D.C operating voltages. Since the a.c leakage current is found to stabilise somewhat after 10 cycles of aging, a comparison bellicen the A.C and D.C leakage current variations for a 10 year period of simulationcan be done. This is derirted in Fig. 2 in the form of normaliscl curves (normalised with respect to the initial leakage current values under $A$. C and D.C respectively). While the increase in leakage current is about 5 fold in case of A.C voltage (after a period of 20 year simultionl, that in the case of D.C-excitation is roughly 4 times (after 10 days $=10$ yrars, accelerated aging). It is also observed that the magnitude of leakage currents in case of D.C is more than double that under A.C [Figs.3(a) \& 4(a)].

\subsection{Barrier Height:}

The barrier height is calculated rom the low voltage D.C characteristics of the arrester element after each cycle of aging. The calculation is based on the following equation:

$$
\rho \cdot=\rho_{\mathrm{o}} \exp \left(\varphi_{\mathrm{b}} / \mathrm{kT}\right)
$$

where

$$
\begin{aligned}
& \rho \quad \text { - resistivity in } \Omega \cdot m \\
& \text { Po. - constant } \\
& \varphi_{b} \text { - barrier height in } \subseteq V \\
& k_{1} \text { - Boltzman constant. } \\
& 8.625 * 10^{-5} \mathrm{ev} /{ }^{\circ} \mathrm{K} \\
& \mathrm{T} \text { - temperature in } \mathrm{li}
\end{aligned}
$$

The variation in barrier height is found to be quite small initially under both A.C and D.C voltages. But, after about 6 to 8 cycles of aging a significantly abrupt decrease" is observed in both cases (Figs. $5 \& 6$ \}.

\subsection{Capacitance and Tan delta:}

The capacitance and tan delta measurements were made at $1 \mathrm{kHz}$ without any external bias voltage. The capacitance values show general decreasing trends under both D.C and $A$. C operating voltages. On the othcrlutind measured tan delta values at the endiof each cycle of aging show a rantoinly varying spread, which is hard to explain. while it exhibits a shictins spectrum of values, with overall increase, in case of D.C, the variation is highly erratic, with some peaks, i॥ case of A.C.

\section{DISCUSSION}

As a real life simulation of Mos under field conditions, it is felt lint: much more need to be done to have a gioud representation of the operatiug atmosphere. Even then, the present schems offers a guideline on how to plan a laboratory simulation of MOS $A$ rivilu life, to study the complexitics of 1 inil life stress degradation.

The leakage current seems to be the best index of degradation, showing a predictable variation with successive cycles of aging. The values of expectest 
leakage currents were calculated based on an, expression given by Y.Fujiwara et al:[.2].

It is observed that the calculated values of leakage currents show matching trend with the observed values, eventhough slight deviations are present. The following features could be observed: from the calculated and observed graphs [Eigs. $3(b) \& 4(b)$ ]:

(i) While the calculated values are more conservative than the observed values in case of D.C voltage aging, it is "reverse in case of A.C voltage aging.

(ii) The leakage current variation with respect to number of aging cycles is determined by the surge current density, element temperature and number of absorbed surges - which were used to compute the theoretical values under both A.C and D.C voltages.

(iii) While the effect of surges on degradation is found to be pronounced at the elevated temperature and operating voltage, the contribution of the thermal stress to aging is less than that of the former.

Considering the barrier height variation, the almost steady value and then the sudden drop evident from the Figs. 5.\& 6 , indicate that irreversible changes in the microstructure of the MOSA material happen only after some cycles of aging. In the present case it is observed that such a change happens after about 8 cycles of aging in case of $D . C \& 6$ cycles of aging in case of A.C. But it is notable that the order of change in case D.C is far more than that in case of A.C. This clearly indicates the polarization effects rume into play in case of an unidirectional excitation $\lceil\overline{3}\rfloor$.

The decreasing capacitance values with number of aging cycles might be the result:": of microstructural changes happering at the depletion region near the zno grain-grain interfaces, in the arrester material. This as well as the erratici... nature of tan delta variation will have to be explained based more on the material characterisation after aging and associated changes in quantum mechanical phenomena, which were outside the scope of the present work. Hence the decision to consider the leakage current and barrier height as the main indices of aging:

\section{CONCLUSIONS}

A simulation of the field conditions under which surge arresters are supposed to operate has been achieved to a fairly good extent in the laboratory. The leakage current through the arrester is found to follow a predictable variatiun opening up possibilities of lif. prediction on the basis of the order uf its variation. Eventhough the gen...l trends of variation in drograblinil indices is similar under both $A . C$.11m? D.C voltages, evidence of lroholily different phenomena of aging is bluswrorl from the tan delta and colur.it.m... variations.

\section{AKNOWLEDGEMENTS}

The assistance of $M r$. B. Raghurum ill setting up the experimental facjlitios is gratefully acknowledged.

\section{REFERENCES}

[1] IEC TC 37 WG-4 AUGUST 1980 "SURGE ARRESTERS - Part 3: Metal Oxidr surro" arresters without gaps for A.C systems"

[2] Y.Fujiwara, Y.Shibuya, M.tmataki $s$ T.Nitta, "Evaluation of sulju Degradation of Metal oxide Sury. Arresters", IEEE Trans. on Pulicy. Apparatus and Systems, Vol. $\Gamma \wedge s-101$, No.4, pp. 978-985, April 1982. [3] M.Oyama, I.Ohshima, M.llonda,
M.Yamashita Performance of zinc oxide elements umler D.C voltage", IEEE Trans. on ruwh. Apparatus and systems, vol. PAS-101, No.6, pp. 1363-1368, June 1982.

-IRIA:RISE/FALL TIMË OB. GQUS

DAIE: Sep $19=30$

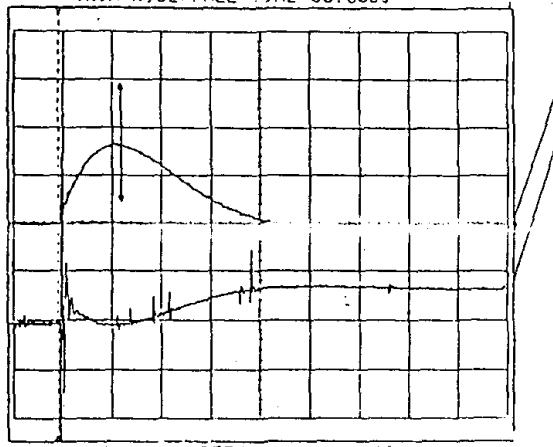

IRIA:PULSE WJOTH $2.348 \mathrm{~ms}$

[1 $191: 03: 19: 52$

IRJA: $0.50 \%:$ In: TR2A: 05.00 : 1904

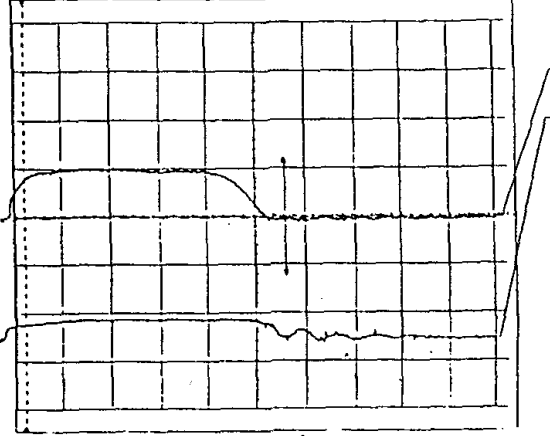

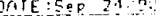
IITE : 16:29:10

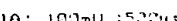
rezh: $05.311: 52,1$

Eig.1 : (a) Typical lightning imml... current wave form

(b) Typical switching impuls. current wave form 


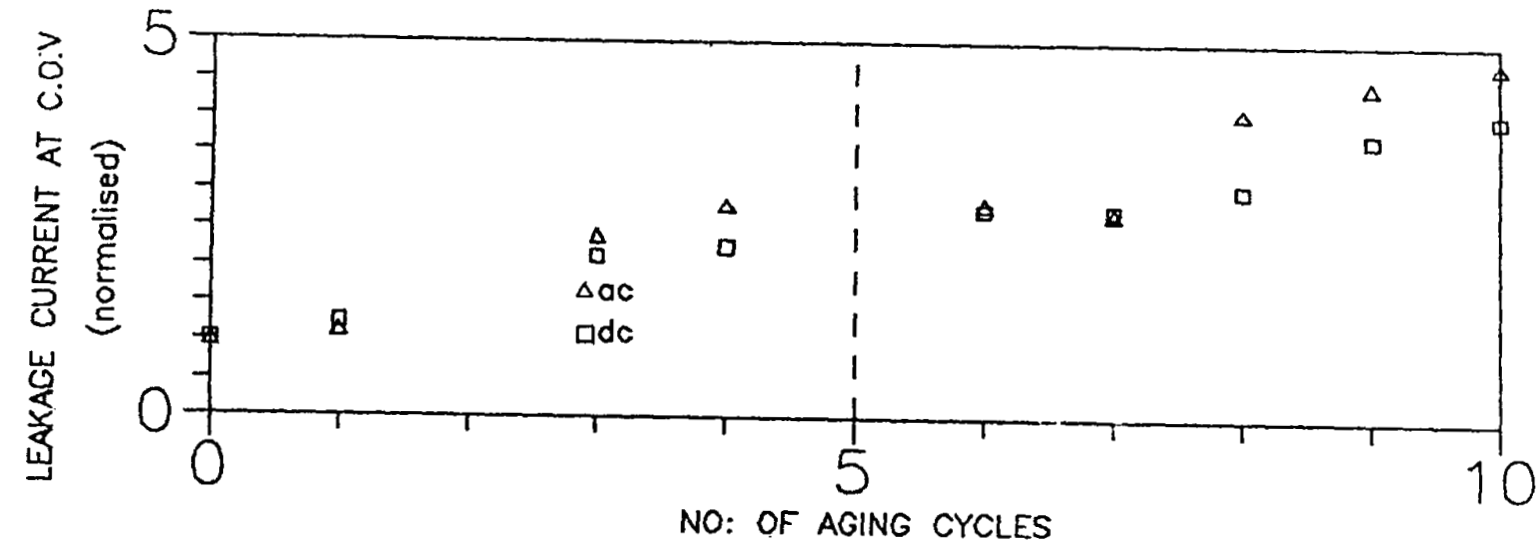

Fig.2 : Comparison between ac \& dc observed leakage currents at

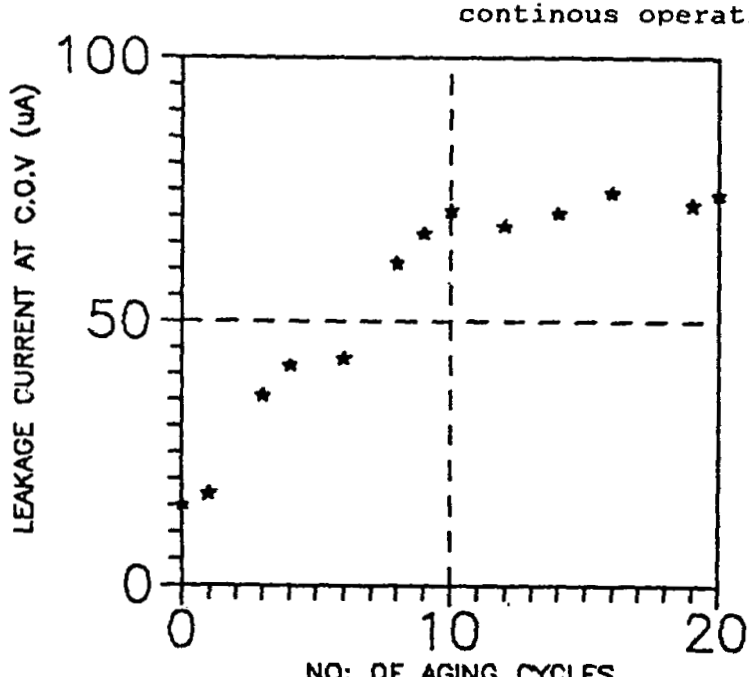

NO: OF AGING CYCLES

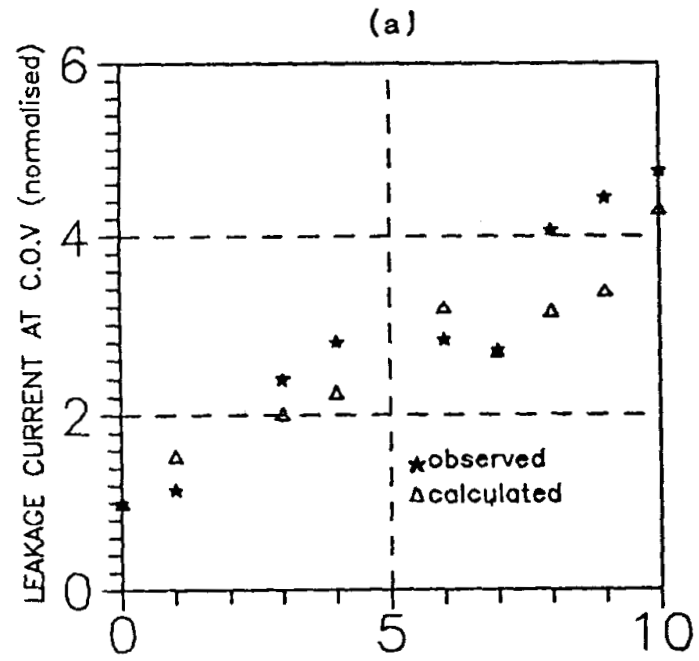

NO: OF AGING CYCLES

(b)
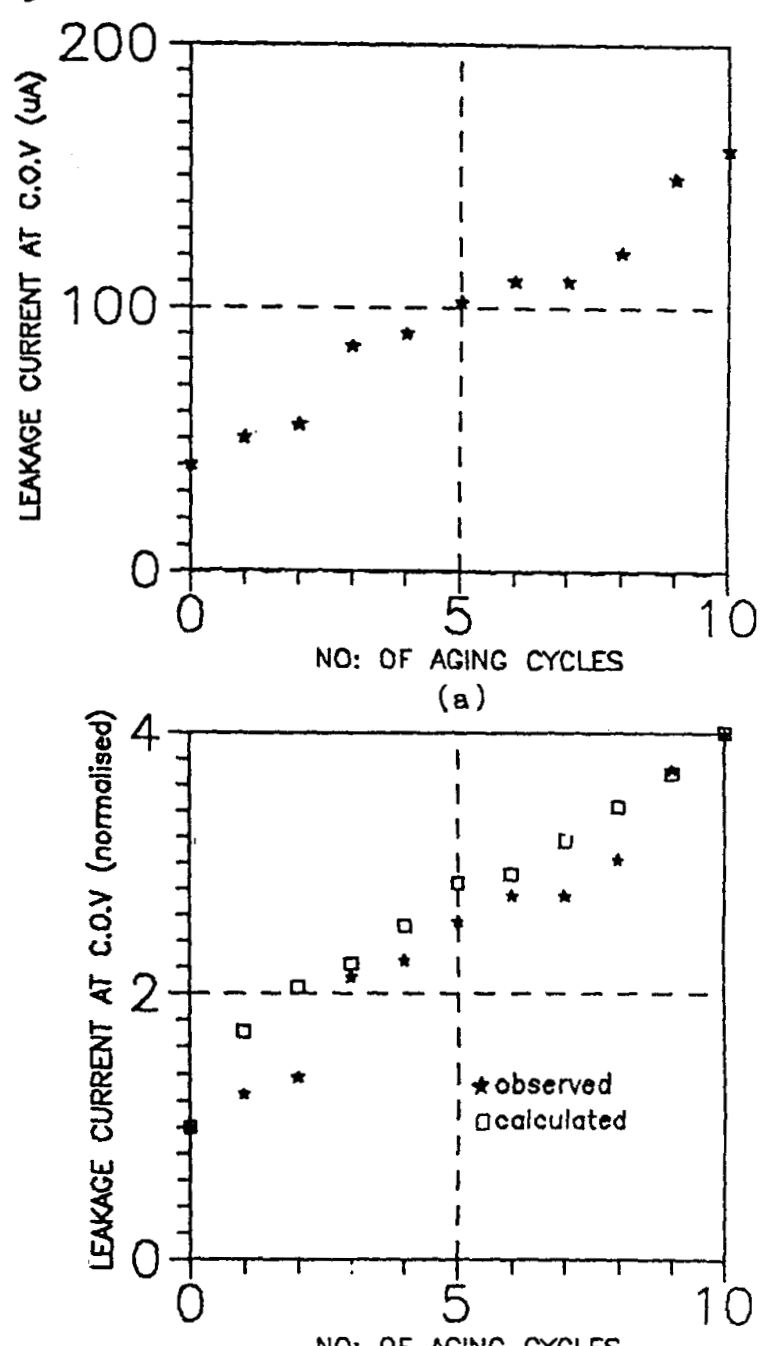

NO: OF AGING CYCLES

(b)

Fig.3 : (a) A.C leakage current at C.o.V (measured at $60^{\circ} \mathrm{C}$ )

(b) Normalised ac leakage currents (observed \& calculated)

Fig.4:(a) D.C leakage current at C.O.V (measured at $60^{\circ} \mathrm{C}$ )

(b) Normalised dc leakage currents (observed \& calculated) 


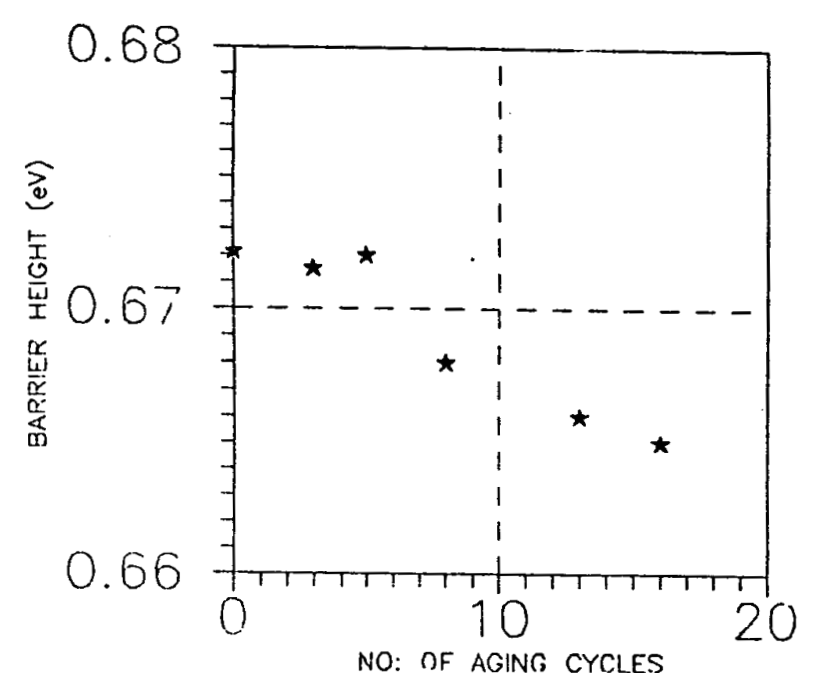

Eig.5 : Barrier height variation after aging under ac, excitation.

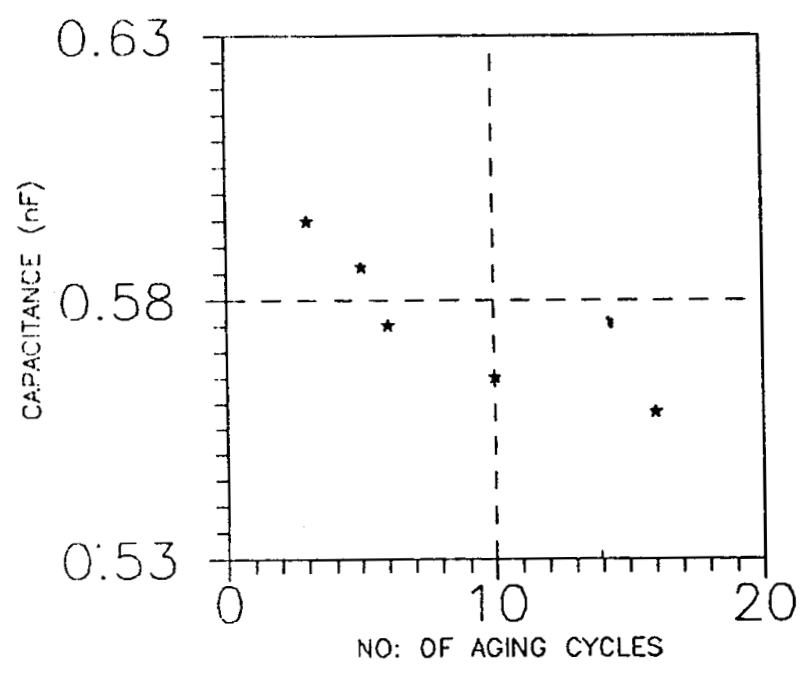

Eig.7 : Capacitance variation after

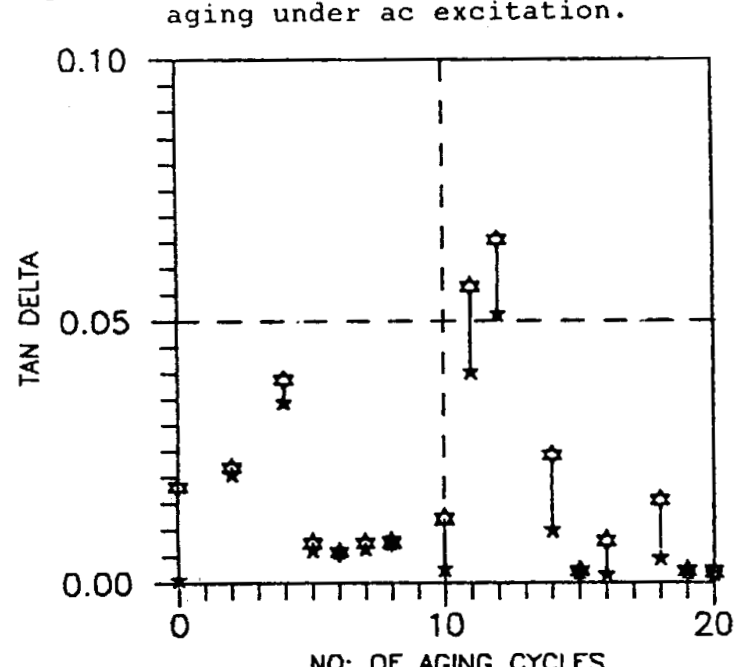

NO: DF AGING CYCLES

Eig.9 : Tan delta variation after aging under ac excitation.

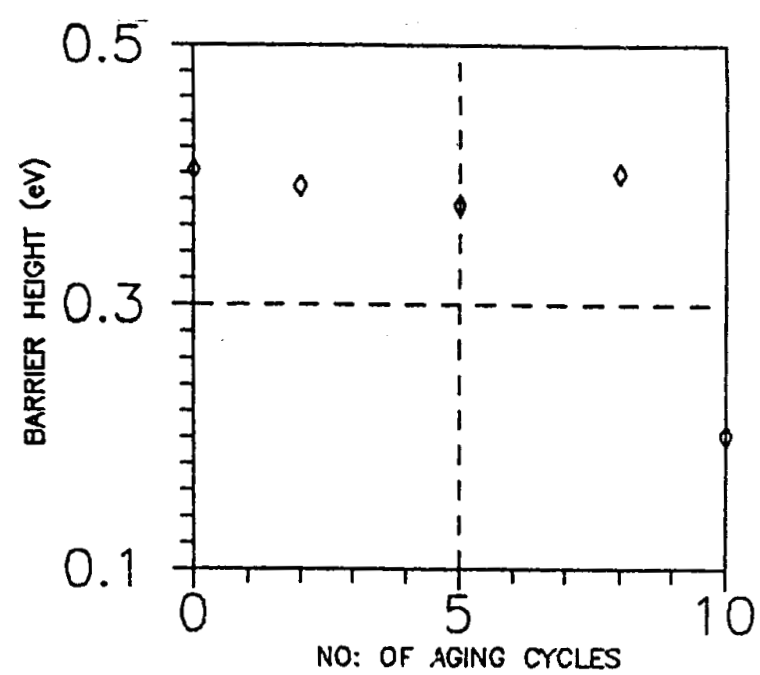

Fig. 6 : Barrier height variation after aging under dc excitation.

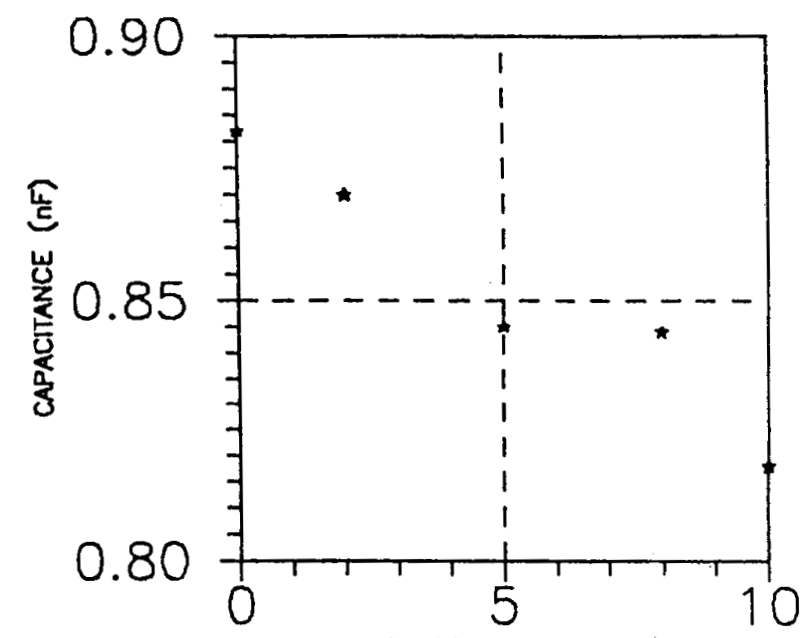

NO: OF AGING CYCLES

Fig.8 : Capacitance variation after aging under de excitation.

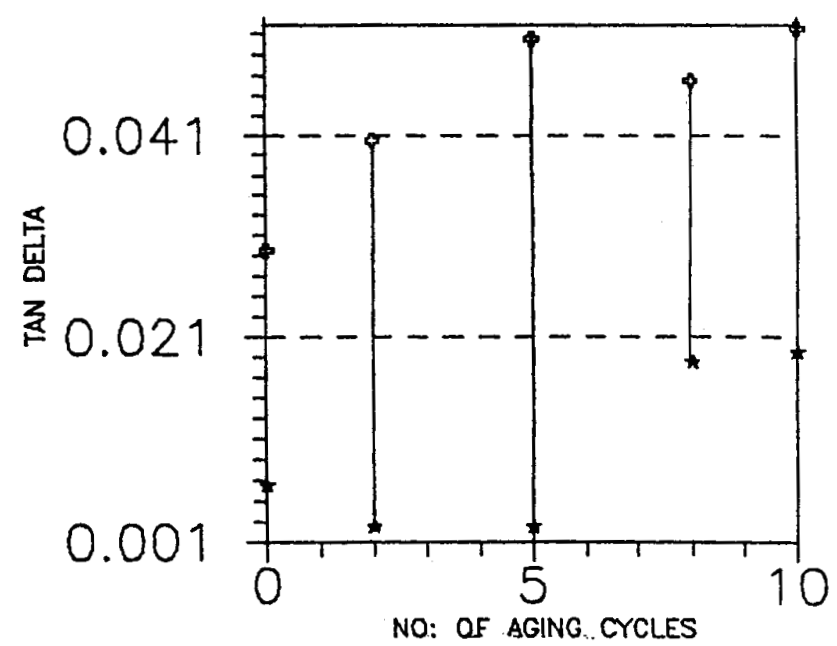

Fig.10: Tan delta variation after aging under dc excitation. 